\title{
A construção institucional do Museu Paraense
}

\section{The institutional constitution of Museu Paraense}

\author{
Geraldo Magella de Menezes Neto \\ Professor da Faculdade Integrada Brasil Amazônia e da Secretaria Municipal de Educação de Belém-PA. \\ geraldoneto53@hotmail.com
}

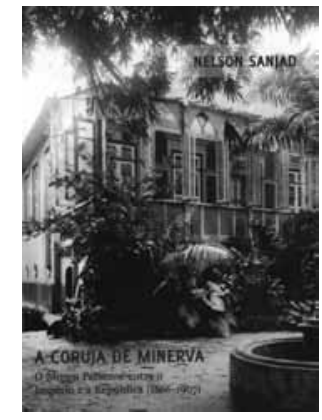

SANJAD, Nelson.

A coruja de Minerva: o

Museu Paraense entre

o Império e a República

(1866-1907). Brasília:

Instituto Brasileiro de

Museus; Belém: Museu

Paraense Emílio Goeldi;

Rio de Janeiro: Fundação

Oswaldo Cruz, 2010.

492p.

$A$ coruja de Minerva: o Museu Paraense entre o Império e a República (1866-1907) é fruto da tese de doutorado de Nelson Sanjad em História das Ciências e da Saúde pela Fundação Oswaldo Cruz, defendida no ano de 2005. A obra ganhou o prêmio Mário de Andrade do Instituto do Patrimônio Histórico e Artístico Nacional na categoria Teses no ano de 2008, sendo então publicada no ano de 2010.

O objetivo do livro é "refletir sobre a construção institucional do Museu Paraense, tendo como pano de fundo a passagem do Império para a República", mais especificamente, "analisar as mudanças políticas que posicionaram o Museu Paraense, após o golpe republicano de 1889, como uma das instituições estaduais prioritárias em termos de aplicação de recursos financeiros e como importante símbolo para a identidade das elites locais" (p.16). O autor utiliza como recorte cronológico o período 1866-1907, que representa respectivamente a fundação do Museu e o término da gestão do zoólogo suíço Emílio Goeldi.

Apesar de não ser historiador de formação, Nelson Sanjad realiza um interessante trabalho de compilação e análise crítica das fontes. Nesse sentido, o grande mérito da obra é justamente a extensa variedade de documentos utilizados, que incluem atas, ofícios, cartas, jornais, leis, relatórios, contratos e fotografias, de vários arquivos em Belém, São Paulo e Rio de Janeiro. Além disso, Sanjad utiliza muitos artigos científicos, inclusive em língua estrangeira, de cientistas de diversas áreas, como zoologia, botânica, ornitologia, entomologia, arqueologia, etnologia etc.

O livro pode ser dividido em duas partes: a primeira, que trata especificamente da história do Museu Paraense, compreende o capítulo 1, "O Museu Paraense no período Imperial" e o capítulo 2, "A reforma do Museu Paraense no período republicano", enfocando principalmente as figuras de Domingos Soares Ferreira Penna, na época do Império, e Emílio Goeldi, na época da República; já a segunda parte compreende o capítulo 3, "Agenda de pesquisa e autoridade científica", e o capítulo 4, "O Museu Paraense e as questões regionais", tratando

http://dx.doi.org/10.1590/S0104-59702013000400020 
especificamente das estratégias de Emílio Goeldi para obter o reconhecimento do Museu como autoridade científica na fauna amazônica, bem como seu envolvimento em questões políticas e de ordem pública, como no caso do Contestado Franco-Brasileiro (1897-1900) e nas pesquisas sobre entomologia médica.

O livro de Sanjad se mostra afinado com os debates da historiografia da denominada história das ciências. O autor é bastante crítico com as hipóteses que tendem a generalizar definições e conceitos sobre os museus de história natural do fim do século XIX. Ele deixa claro que o seu argumento "não deve ser confundido com um tipo de história positivista das ciências que classifica o regime imperial como pré-científico e o republicano como científico", nem com "uma tentativa de delimitação da origem de uma 'ciência nacional' e autônoma" (p.19).

A obra de Nelson Sanjad também representa uma nova perspectiva para a historiografia do Museu Paraense Emílio Goeldi, que é profundamente influenciada pelos escritos do zoólogo e memorialista Osvaldo Rodrigues da Cunha, textos muitas vezes tomados como a história 'oficial' do Museu (Cunha, 1989). Cunha, cuja produção se inicia nos anos 1950, trabalha com a ideia de que a história do Museu Paraense poderia ser contada "como uma sucessão de fases, alternando-se esplendor e decadência, vigília e sono. Essas fases são entendidas como uma cronologia evolutiva da instituição, iniciada com uma fase 'pré-científica' e finda com o que surgia, na década de 1950, como 'Ciência pura'” (Sanjad, 2001, p.114). Apesar de Sanjad trabalhar com a ideia de que a passagem do Império para a República constitui-se um 'marco' na história do Museu, o que também é percebido por Cunha, sua obra se diferencia porque relaciona a transformação do Museu Paraense no início da República com o projeto político dos primeiros governadores republicanos, que viam no Museu um elemento de 'instrução do povo', pelo qual se chegaria ao 'progresso da nação', ideias profundamente influenciadas pelo positivismo.

Nesse sentido, ao analisar o Museu na passagem do Império para a República, o autor toma o cuidado de não adotar o discurso dos republicanos, o qual muitos pesquisadores acabaram incorporando em seus estudos sobre a história do Museu Paraense, inclusive Osvaldo Cunha. Assim, a ideia de evolução da instituição, que a apresenta sob uma interpretação positiva em relação ao período republicano e sob uma interpretação negativa em relação ao período imperial, é criticada por Nelson Sanjad, que estuda "o contexto de criação do Museu e os significados que a instituição adquiriu para a elite dirigente no Pará durante o império" (p.40).

$\mathrm{Na}$ abordagem do Museu no período imperial, Sanjad discute os problemas enfrentados para a manutenção da instituição, como a instabilidade política, marcada pela rotatividade dos presidentes da província do Pará somada à dificuldade da instituição em obter recursos da Assembleia Provincial. Conforme aponta o autor, os maiores investimentos na época foram o calçamento das ruas com pedras de lioz portuguesas, o Teatro da Paz e o Paço Municipal, "ícones de modernidade e civilização eleitos pela elite paraense" (p.86), em detrimento do pouco investimento no Museu Paraense no mesmo período.

Ainda no contexto imperial, ao realizar uma análise da trajetória de Ferreira Penna, Sanjad contesta vários pesquisadores, que, equivocadamente, vinculavam a obra científica de Ferreira Penna ao Museu Paraense. Segundo Sanjad, a obra de Penna teve como "interlocutor, financiador e veículo de divulgação o Museu Nacional, sua revista e seus funcionários", sendo 
assim, não houve "uma única pesquisa concluída ou publicação" levada pelo Museu Paraense nos seus primeiros 23 anos (p.120).

Para o autor, a ruptura política de novembro de 1889 “'salvou' o Museu Paraense de um fim definitivo" (p.156). Nesse contexto, Sanjad destaca a reforma educacional empreendida por José Veríssimo, que restaurou o Museu, e a contratação do zoólogo suíço Emílio Goeldi no governo de Lauro Sodré. Goeldi deu ao Museu "um perfil claramente definido, conservando 'estritamente o caráter de estabelecimento para a cultura das ciências naturais e da etnologia amazônicas'” (p.183). As medidas tomadas por Goeldi incluíam a transferência do Museu para uma nova sede, com a formação de uma 'colônia científica', e a 'europeização' do espaço do Museu, com a criação do jardim zoológico e o horto botânico, além da contratação de uma série de profissionais estrangeiros, "em início de carreira, embora efetivamente treinados em instituições e ateliês de história natural" (p.213).

Nelson Sanjad também destaca a atividade científica de Emílio Goeldi, que construiu uma agenda de pesquisa com o objetivo de angariar 'autoridade científica' em relação aos estudos sobre a fauna amazônica. Além das publicações na revista da instituição, o Boletim do Museu Paraense de História Natural e Etnografia, Goeldi manteve um intenso intercâmbio com cientistas e instituições, inclusive da Europa, enviando artigos e espécies coletadas. O autor destaca que Goeldi foi “extremamente hábil na percepção dos 'vácuos de autoridade' existentes no conhecimento zoológico da Amazônia, assim como na seleção de problemas irresolutos e temas que se apresentavam ou emergiam como 'campos de batalha'" (p.287). Interessante nesse sentido é o debate de Goeldi com o diretor do Museu Paulista, Hermann von Ihering, sobre os ninhos do japu. Segundo Sanjad, a controvérsia estava longe de ser uma 'divergência de opiniões', mas “uma disputa pela liderança nas pesquisas ornitológicas realizadas no Brasil, mantida justamente pelos dois 'museus científicos'” (p.270).

O livro de Sanjad também demonstra a relação de Goeldi com as autoridades no chamado Contestado Franco-Brasileiro. Goeldi fez duas expedições ao Amapá para proceder a um inventário científico da região para auxiliar a posição brasileira contra a França, que reivindicava o território apoiada nos estudos de Henri Coudreau. Nelson Sanjad mostra que, mais do que produzir o inventário científico, Goeldi atuou no caso como uma espécie de 'espião', transmitindo informações às autoridades brasileiras sobre a comissão suíça que iria arbitrar a questão. Nesse sentido, é notável o esforço de Sanjad em reconstruir cada passo da estratégia brasileira, apoiado nas cartas trocadas entre Goeldi e o barão do Rio Branco.

Emílio Goeldi também se voltou para o ramo da entomologia médica, estudando várias espécies de mosquitos, num momento em que não apenas havia "a emergência da entomologia médica como disciplina autônoma", mas também "o aumento de casos de febre amarela em Belém e uma maior atenção do poder público estadual para a saúde pública" (p.346). Sanjad aponta a pouca atenção dada pelos pesquisadores a esses estudos de Goeldi, menor do que a dada aos trabalhos ornitológicos, mas "não menos importante em razão da densidade desses estudos e da repercussão que tiveram no meio científico" (p.359).

Podemos relacionar a abordagem de Nelson Sanjad sobre o envolvimento de Emílio Goeldi com as autoridades no chamado Contestado Franco-Brasileiro e os estudos do zoólogo sobre a entomologia médica com o que Moema Vergara identificou como "profunda reorientação teórico-metodológica" experimentada na historiografia brasileira da ciência após os anos 
1970. Os trabalhos a partir desse contexto começaram a ver "as instituições científicas como agentes da implantação de práticas e conhecimentos científicos, sobretudo no que diz respeito à 'análise da influência de fatores extracientíficos no processo de produção de conhecimentos'” (Vergara, 2004, p.27). De fato, o livro de Sanjad sugere que Goeldi, mesmo tendo que se distanciar de sua pesquisa inicial por causa de demandas externas, soube reverter isso em benefício do Museu Paraense, conseguindo mais apoio para desenvolver seus projetos na instituição.

Desse modo, a obra de Nelson Sanjad, mesmo reforçando 'mitos' da história do Museu Paraense como Ferreira Penna e Emílio Goeldi, aponta novas perspectivas para a abordagem dos museus de ciência da virada do século XIX para o XX. A utilização de uma extensa e variada relação de fontes contribuiu para que o autor refutasse várias questões cristalizadas pela historiografia e chegasse a novas considerações, que podem influenciar futuras pesquisas na área da história das ciências. A caprichada edição do livro, com várias imagens e fotografias da época, também colabora para que a obra se torne uma interessante leitura sobre a história do Museu Paraense.

\section{REFERÊNCIAS}

CUNHA, Osvaldo Rodrigues da.

Talento e atitude: estudos biográficos do Museu Emílio Goeldi. Belém: Museu Paraense Emílio Goeldi. 1989.

SANJAD, Nelson.

Bela adormecida entre a vigília e o sono: uma leitura da historiografia do Museu Paraense Emílio Goeldi, 1894-2000. In: Faulhaber, Priscila; Toledo, Peter Mann de (Org.). Conhecimento e fronteira: história da ciência na Amazônia. Belém: Museu Paraense Emílio Goeldi. p.113-145. 2001.

VERGARA, Moema de Rezende.

Ciência e modernidade no Brasil: a constituição de duas vertentes historiográficas da ciência no século XX. Revista da SBCH, São Paulo, v.2, n.1, p.22-31. 2004. 